\title{
A case of rheumatoid pericarditis with high concentrations of interleukin- 6 in pericardial fluid
}

\author{
N Shikama, T Terano, A Hirai
}

\begin{abstract}
A case of rheumatoid pericarditis that developed into cardiac tamponade without deterioration of rheumatoid arthritis is described. The concentration of interleukin-6 (IL-6) in pericardial fluid was notably increased compared with serum. IL-6 may be associated with progression or maintenance of rheumatoid pericarditis.

(Heart 2000;83:711-712)
\end{abstract}

Keywords: rheumatoid pericarditis; cardiac tamponade; interleukin-6

The frequency of pericarditis in patients with rheumatoid arthritis has been reported to range between $30-50 \%,{ }^{12}$ but cardiac tamponade is a rare complication in such patients. The progression of cardiac tamponade caused by rheumatoid pericarditis is not necessarily due to deterioration of rheumatoid arthritis, and the prognosis of patients is very poor. However, rheumatoid pericarditis is absent from the index to the activity of disease. We report a case of cardiac tamponade caused by rheumatoid pericarditis associated with high concentrations of interleukin-6 (IL-6) in pericardial fluid.

A 60 year old Japanese woman was admitted to hospital with cardiac tamponade. The patient had been treated with non-steroidal anti-inflammatory drugs after the initial diagnosis of rheumatoid arthritis (rheumatoid factor $120 \mathrm{IU} / \mathrm{ml}$ ) when she was 47 years old. At the age of 59 years, she was also diagnosed as having a moderate pericardial effusion caused by rheumatoid arthritis, based on chest radiographic and echographic findings. Since 1997, the patient has been on prednisolone (20 $\mathrm{mg} /$ day) for treatment of massive pericardial effusion. In March 1998, she experienced worsening of her dyspnoea and palpitations upon exertion, while her rheumatoid arthritis remained stable. Therefore, she was referred to our hospital for further management.

Physical examination on admission revealed her body temperature was $36.5^{\circ} \mathrm{C}$, blood pressure was $138 / 98 \mathrm{~mm} \mathrm{Hg}$, and pulse rate was 115 beats/min and irregular; besides Gallop rhythm, slight bilateral pulmonary rales and peripheral oedema were present. A chest radiograph showed severe cardiomegaly with moderate pulmonary congestion. An ECG showed sinus tachycardia with supraventricular premature contraction (heart rate of 122 beats/min) and low voltage in all leads. Echocardiography showed massive pericardial effusion around the heart with slightly diastolic collapse of both ventricles and slightly dilated left atrial dimension.
Table 1 Concentrations of cytokines in serum or plasma and pericardial fluid

\begin{tabular}{lccc}
\hline & $\begin{array}{l}\text { Serum } \\
(p g / m l)\end{array}$ & $\begin{array}{c}\text { Plasma } \\
(p g / m l)\end{array}$ & $\begin{array}{l}\text { Pericardial fluid } \\
(p g / m l)\end{array}$ \\
\hline IL-1 $\beta$ & 2.42 & & 1.05 \\
IL-6 & 4.33 & 2950 \\
IL-8 & $10.0>$ & 19.1 & 233 \\
VEGF & & 197.0 \\
\hline
\end{tabular}

VEGF, vascular endothelial growth factor.

Laboratory data included the following: white blood cell count of $8.5 \times 10^{3} / \mathrm{mm}^{3}$ (with $74.9 \%$ neutrophils, $18.7 \%$ lymphocytes, and $6.1 \%$ monocytes); red blood cell count of $4.84 \times 10^{6} / \mathrm{mm}^{3}$; haemoglobin concentration of $14.6 \mathrm{~g} / \mathrm{dl}$; haematocrit of $43.4 \%$; platelet count of $23.3 \times 10^{4} / \mathrm{mm}^{3}$; total serum protein concentration of $7.3 \mathrm{~g} / \mathrm{dl}$; serum albumin concentration of $3.9 \mathrm{~g} / \mathrm{dl} ; 28 \mathrm{IU} / 1$ aspartate aminotransferase; $25 \mathrm{IU} / 1$ alanine aminotransferase; $593 \mathrm{IU} / 1$ lactate dehydrogenase; $33.5 \mathrm{mg} / \mathrm{dl}$ blood urea nitrogen; $0.9 \mathrm{mg} / \mathrm{dl}$ creatinine; $201 \mathrm{IU} / 1$ creatine kinase; $1.2 \mathrm{mg} / \mathrm{dl}$ C-reactive protein; rheumatoid factor of $5 \mathrm{IU} / \mathrm{ml}$; and no antinuclear antibody.

Cardiac tamponade was diagnosed and pericardiocentesis was performed, yielding $1600 \mathrm{ml}$ of serous fluid. Laboratory data of the fluid included $130 \mathrm{mg} / \mathrm{dl}$ glucose, $3.9 \mathrm{~g} / \mathrm{dl}$ total protein, 283 IU/1 lactate dehydrogenase, and $7.1 \mathrm{IU} / 1$ adenosine deaminase. Bacterial culture of the fluid showed no bacterial infection. Cytologic examination of the fluid showed no malignant cells, and only a few histiocytes were detected in the fluid. Cytokines were measured in serum and pericardial fluid and their values are shown in table 1 . The patient has since developed cardiac tamponade three times during the 12 month follow up period following her discharge. On each occasion, she was subjected to pericardiocentesis and prednisolone was administered intrapericardially, because she did not want surgical intervention.

\section{Discussion}

It has been reported that in patients with rheumatoid arthritis the activity of disease is associated with high concentrations of cytokines in serum and in synovial fluid or fibroblast like synoviocytes. Particularly, overexpression of IL-6 has been implicated in the pathogenesis of rheumatoid arthritis. ${ }^{3-7}$ However, to the best of our knowledge, there have been no reports of an association between pericarditis and cytokines concentrations in pericardial fluid of patients with rheumatoid arthritis. In the present patient, rheumatoid pericarditis developed into cardiac tamponade without deterioration of rheumatoid arthritis, and IL- 6 and IL-8 concentrations in pericardial fluid were 
increased. Moreover, there was a very large difference between the concentration of IL- 6 in pericardial fluid and that in serum (2950 v $4.33 \mathrm{pg} / \mathrm{ml}$ ). This could account for the difference in the activity of the disease between the pericarditis and arthritis in our patient. The possibility remains that IL- 6 is associated with progression or maintenance of rheumatoid pericarditis. Therefore, IL-6 concentrations in pericardial fluid may serve as an index of response to treatment in patients with rheumatoid pericarditis. Also, a recent study has suggested that in vivo blockade of IL-6 signals by the administration of an anti-IL- 6 monoclonal antibody was clinically effective in patients with rheumatoid arthritis. ${ }^{8}$ It could be expected that correction of dysregulated IL-6 production was useful in the treatment of rheumatoid pericarditis. However, the relation between the cytokines concentrations in pericardial fluid and activity of the disease remains to be verified.

1 Bonfiglio T, Atwater EC. Heart disease in patients with seropositive rheumatoid arthritis: a controlled autopsy study and review. Arch Intern Med 1969;124:714-9.

2 Nomeir AM, Turner R, Watts E, et al. Cardiac involvement in rheumatoid arthritis. Ann Intern Med 1973;79:800-6.

3 Hirano T, Matsuda T, Turner M, et al. Excessive production of interleukin $6 / \mathrm{B}$ cell stimulatory factor-2 in rheumatoid arthritis. Eur F Immunol 1988;18:1797-801.

4 Houssiau FA, Devogelaer JP, van Damme J, et al. Interleukin-6 in synovial fluid and serum of patients with rheumatoid arthritis and other inflammatory arthritides. Arthritis Rheum 1988;31:784-8.

5 Guerne PA, Zuraw BL, Vaughan JH, et al. 7 Clin Invest 1989;83:585-92.

6 Firestein GS, Alvaro-Gracia JM, Maki R. Quantitative analysis of cytokine gene expression in rheumatoid

7 Okamoto H, Yamamura M, Morita Y, et al. The synovial Okamoto $\mathrm{H}$, Yamamura $\mathrm{M}$, Morita $\mathrm{Y}$, et al. The synovial
expression and serum levels of interleukin- 6 , interleukin11 , leukemia inhibitory factor, and oncostatin $M$ in rheumatoid arthritis. Arthritis Rheum 1997;40:1096-105.

8 Wendling D, Racadot E, Wijdenes J. Treatment of severe rheumatoid arthritis by anti-interleukin 6 monoclonal antibody. $\mathcal{F}$ Rheumatol 1993;20:259-62.

\section{IMAGES IN CARDIOLOGY}

\section{Coronary artery fistula dependent systemic perfusion}

A premature newborn male (29th week gestation, birth weight $890 \mathrm{~g}$ ) was referred for investigation of a heart murmur. Echocardiography showed a double outlet right ventricle with hypoplastic left ventricle, ventricular septal defect, critical subvalvar and valvar stenosis without detectable flow across the aortic valve, left sided interrupted aortic arch type B, ductus, persistent left superior vena cava draining into the coronary sinus. In addition, an abnormal vessel between the main pulmonary artery and the aortic root was seen, which showed a flow from the pulmonary artery to the ascending aorta. This led to the differential diagnosis of an aortopulmonary window or a coronary fistula.

To clarify the diagnosis, cardiac catheterisation was performed from the femoral vein $(4 \mathrm{~F}$ sheath). Pulmonary angiography showed a coronary fistula with contrast flow from the main pulmonary artery (PA) to the aorta. A selective injection into the pulmonary orifice of the fistula in a laid back view clearly showed the contrast flow through the fistula of the left coronary artery into the ascending aorta (AAo) and subsequently the right brachiocephalic trunk and left common carotid artery (fig). An angiographic run after blocked injection into the main pulmonary artery revealed a relatively small left atrium, a restrictive foramen ovale, and a double outlet right ventricle with functional mitral and aortic atresia.

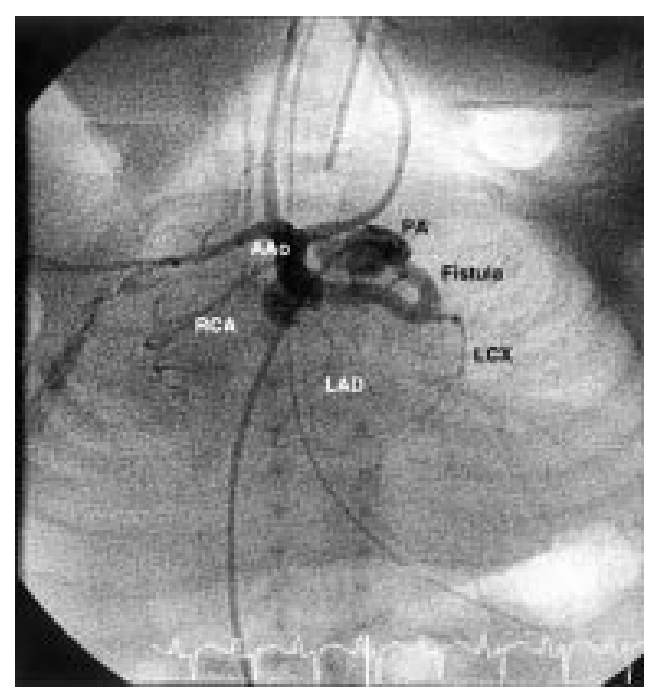

In this patient a coronary artery fistula between the aorta and pulmonary artery was the only source of antegrade perfusion into the ascending aorta in functional aortic atresia and interrupted aortic arch through retrograde coronary artery flow.

C JUX

R KAULITZ G HAUSDORF 